\title{
Knowledge about hypertension and factors associated with the non-adherence to drug therapy ${ }^{1}$
}

\author{
Mayckel da Silva Barreto ${ }^{2}$ \\ Annelita Almeida Oliveira Reiners ${ }^{3}$ \\ Sonia Silva Marcon ${ }^{4}$
}

\begin{abstract}
Objectives: to identify the degree of knowledge of people with hypertension concerning the disease and to verify the factors associated with the non-adherence to anti-hypertensive drug therapy. Method: Cross sectional study, involving 422 people. Data collection took place at their homes, between December 2011 and March 2012, through interviews using the following instruments: Medication Adherence Questionnaire (MAQ-Q), Medication Regimen Complexity Index (MRCI) and a guide with questions related to sociodemographic profile, satisfaction with healthcare service and knowledge about the disease. Results: $42.6 \%$ did not adhere to the drug therapy and $17.7 \%$ had poor knowledge about the disease. Factors associated with the nonadherence were: complex drug therapy, poor knowledge about the disease and dissatisfaction with the healthcare service. Conclusion: The findings reinforce that the complex drug therapy prescriptions, little knowledge about the disease and dissatisfaction with the healthcare service have influence on the process of non-adherence to anti-hypertensive drug therapy.
\end{abstract}

Descriptors: Hypertension; Medication Adherence; Risk Factors; Health Knowledge, Attitudes, Practice; Nursing.

\footnotetext{
${ }^{1}$ Paper extracted from master's thesis "Non compliance drug treatment in individuals with arterial hypertension in Maringá - Paraná" presented to Universidade Estadual de Maringá, Maringá, PR, Brazil. Supported by Conselho Nacional de Desenvolvimento Científico e Tecnológico (CNPq), process \# 485807/2011-4.

${ }^{2}$ Doctoral student, Universidade Estadual de Maringá, Maringá, PR, Brazil. Professor, Faculdade de Filosofia Ciências e Letras de Mandaguari, Mandaguari, PR, Brazil.

${ }^{3} \mathrm{PhD}$, Associate Professor, Departamento de Enfermagem Médico-Cirúrgica, Universidade Federal do Mato Grasso, Cuiabá, MT, Brazil.

${ }^{4} \mathrm{PhD}$, Associate Professor, Centro de Ciências da Saúde, Universidade Estadual de Maringá, Maringá, PR, Brazil.
}

Corresponding Author:

Mayckel da Silva Barreto

Faculdade de Filosofia Ciências e Letras de Mandaguari

Rua Renê Táccola, 152

Centro

CEP: 86975-000, Mandaguari, PR, Brasil

E-mail: mayckelbar@gmail.com
Copyright @ 2014 Revista Latino-Americana de Enfermagem This is an Open Access article distributed under the terms of the Creative Commons Attribution Non-Commercial License (CC BY-NC).

This license lets others distribute, remix, tweak, and build upon your work non-commercially, and although their new works must also acknowledge you and be non-commercial, they don't have to license their derivative works on the same terms. 


\section{Introduction}

Systemic Arterial Hypertension (SAH), when not controlled, is still being a significant medical and social problem in developed and developing countries. Even knowing the efficacy, effectiveness and efficiency of many available preventive and control measures, the negative effects caused by the disease will probably continue for decades, representing one of the biggest social and health related challenges ${ }^{(1)}$.

One of the main causes of the negative effects caused by $\mathrm{SAH}$ is the non-adherence to hypertensive treatment, as well as the late diagnosis and the prolonged asymptomatic course of the disease, which resulted in the development of studies in the area ${ }^{(2-5)}$. Estimates point out that the degree of the non-adherence to the treatments of Chronic Diseases (CD) worldwide ranges from $25 \%$ to $50 \%{ }^{(6)}$.

The non-adherence to the drug therapy in cases of $C D$, usually verified through the Morisky-Green-Levine test $^{(7)}$, is considered a complex and multi determined event associated with low socioeconomic levels, complex prescription regimens and dissatisfaction with the healthcare service, which are factors that prevail among the population with $\mathrm{SAH}^{(4,8-11)}$.

Another explanation for the high rate of nonadherence is that many patients do not understand the disease and the drug therapy. The asymptomatic course of the SAH contributes to this lack of understanding and, as a result, many people believe that the disease is intermittent and can be treated exclusively with non-medication therapies, such as stress relief or homemade medication ${ }^{(10)}$.

The relationship between the non-adherence to the SAH treatment and the patient's knowledge about the disease and therapeutic regimen has been reported $(4-6,10)$. However, this relationship requires further evidence ${ }^{(5,12)}$. Moreover, in order for the healthcare professionals to act more effectively, by proposing and implementing actions that meet the real needs of this population, it is necessary to identify the patients who do not adhere to the treatment and their characteristics, and the reasons why this occurs.

Based on the above, the present study was aimed at: identifying the degree of knowledge of people with arterial hypertension about the disease and verifying the factors associated with the non-adherence to the antihypertensive drug therapy.

\section{Method}

Cross sectional, descriptive study, involving people with $\mathrm{SAH}$, undergoing outpatient care treatment at the Primary Healthcare Service in a city located in the South region of Brazil, which had 25 primary healthcare units (UBS) and 65 teams of the Family Health Strategy (ESF) at the time of data collection. For the purposes of this research, the area covering the 23UBS located within the perimeter of the city was used by convenience.

The size of the sample was calculated based on the total of people with SAH registered in the city $(40,073)$. It was assumed that $50 \%$ of people could have the characteristic of interest (non-adherence) ${ }^{(6)}$, estimation error of $5 \%$, and a confidence interval of $95 \%$. $10 \%$ more was added for possible losses, resulting in a stratified and randomly selected sample of 422 people, with a distribution that was proportional to the total number of people with SAH registered in each UBS of the urban area.

As inclusion criteria, the following was considered: to be 18 years old or more and to have started drug therapy for at least one year, since the interruption of antihypertensive treatment occurs more often in the first months after it starts, with $11 \%$ to $22 \%$ of the cases occurring in the first year ${ }^{(6)}$. Seventeen people were excluded, including two women who used antihypertensive drugs only during pregnancy and 15 people with a psychiatric diagnosis of acute mental disorder because they tend not to adhere to the therapy due to the own nature of the disease, besides the fact that many of them relied on other people to properly take the continuous use medication.

For data collection, a list divided by UBS was firstly obtained from the City Health Council with records of the people with $\mathrm{SAH}$, who were given a number. Through an electronic draw, those people who would be interviewed were selected. If the selected person did not meet the inclusion criteria or if they refused to participate in the research, the next person on the list was automatically invited to participate in the study, and this was repeated for up to three times.

After obtaining the addresses and telephone numbers of the people selected, which took place at the UBS, the data collection was conducted and happened during the period from December 2011 and March 2012, through home visits with the use of a semi-structured guide composed of questions related to the sociodemographic profile, health monitoring and knowledge about the disease, which was completed by 
the researcher. The economic level was defined on the basis of the Economic Classification Criteria of Brazil (Brazilian Association of Research Companies - ABEP) which is based on the educational level and consumer goods and is used to estimate the spending power of people and families. In this study, the eight possible levels (A1-A2-B1-B2-C1-C2-D-E) were grouped into two levels $A / B$ and $C / D / E$.

\section{Procedures and data analysis}

The dependent variable was the non-adherence to the hypertensive drug therapy. An instrument of indirect evaluation was used for its measurement, the Medication Non-Adherence Questionnaire (MAQ-Q) of the Qualiaids team, developed to address the act (if the person takes their medication and how much they take), the process (how they take the medication), and the result of adherence (in this case, if the blood pressure is controlled)(13).

The developed and validated instrument ${ }^{(13)}$ takes into account the statement of the participant as a source of information and has three questions, the two first being based on the last seven days, 1) On which days of the week you did not or you did take more than at least one pill of this medication?; 2) On these days, how many pills you did not take, or took more than it was prescribed?; 3) How was your blood pressure when you last measured it?. It is important to note that there was no time restriction for this last question.

The answers resulted in a combined measurement, in which only the people who reported to have taken between $80 \%$ and $120 \%$ of the prescribed dosages were considered adherent. These values are obtained by multiplying the number of pills taken by the number of times, and dividing it by the number of pills prescribed multiplied by the number of times. Finally, the result is multiplied by one hundred.

Adherence was also conditioned to the adequate intake, that is, without "breaks" (not taking any medication for one day), "change of time" (taking the correct dose, but at wrong times), "change of dose" (increasing or reducing the amount of the medication or between medications), "erratic intake" (not taking the medications in various days and times), "half adherence" (taking one medication correctly and another incorrectly), "partial interruption" (stopping taking one or more of their medications), "interruption" (not taking any dose of all medications in the last seven days) and to the report that the BP was normal in the last measurement (clinical outcome).
It was chosen to use the MRCI because it is a comprehensive instrument, which includes three different dimensions of the construct related to the adherence (dose intake, behavior related to the medication and clinical outcome), provides the same effectiveness as the concomitant use of other instruments and enables easier and quicker application(13).

\section{Independent variables}

The knowledge about the disease was verified using 10 questions, with dichotomous answers (yes/ no $)^{(8)}$. Through the instrument, people who answers all the questions correctly receive a score 10 (100\%) and those who answer them all incorrectly receive a zero. Similarly to another study ${ }^{(10)}$, the knowledge was considered satisfactory for those with scores equal or above seven (70\%) and dissatisfactory for the others in this investigation.

As for the complexity of the drug therapy, this was assessed through the Medication Regimen Complexity Index (MRCI), a valid instrument ${ }^{(14)}$ in which the final score is obtained by adding the scores of the three sections - A, B and C - and the higher the score, the more complex the drug therapy ${ }^{(14)}$. The first section has information about dosage ways; the second, about the frequency of doses; and the third, additional information such as specific times, breaking or crushing the pill and concomitant use with food.

The satisfaction of the user with the healthcare service was estimated based on eight questions, two being related to the structure and access to the service, three to the assistance, treatment and care provided by the professionals at the UBS, two to the satisfaction with the treatment and with the doctor, and one to the general satisfaction. The score scale of answers is the Likert type with four possible alternatives, one representing maximum satisfaction and four, total dissatisfaction. After obtaining the average scores, the median divided the sample into groups of "more satisfied" and "less satisfied", as used in another study(4).

The information was entered into an Excel for Windows $2007^{\circledR}$ spreadsheet and later statistically analyzed through the software Statistical Analysis System - SAS ${ }^{\circledR}$. The variables of interest were dichotomized. In the logistic regression of the type Stepwise Backward Elimination, all the variables were inserted and after the application of the tests, only the variables with statistical significance with $p<0.20$ were kept in the adjusted model. In order to verify the extent of the association, the Relative Risk (RR) of the variables 
was calculated, which remained in the final model of the logistic regression at 5\% significance level.

The study complied with the guidelines of Resolution 196/96 of the National Health Council, and its project was approved by the Permanent Research Ethic Committee involving human beings of the Universidade Estadual de Maringá (Opinion 631/2011).

\section{Results}

Based on the combined measurement of the MRCI, it was found that 180 (42.65\%) people were considered to be non-adherent to the antihypertensive drug therapy (Table 1).

Table 1 - Univariate analysis of the association between the non-adherence to drug therapy and bio-socioeconomic and health monitoring related factors concerning hypertensive patients. Maringa, PR, Brazil, 2012

\begin{tabular}{|c|c|c|c|c|c|c|c|}
\hline \multirow{3}{*}{ Variables } & \multicolumn{4}{|c|}{ Adherence } & \multirow{2}{*}{\multicolumn{2}{|c|}{ Total }} & \multirow{3}{*}{$\mathbf{p}$} \\
\hline & \multicolumn{2}{|c|}{ No } & \multicolumn{2}{|c|}{ Yes } & & & \\
\hline & $\mathbf{n}$ & $\%$ & $\mathbf{n}$ & $\%$ & $\mathbf{n}$ & $\%$ & \\
\hline Gender & & & & & & & 0.14 \\
\hline Female & 98 & 23.22 & 153 & 36.26 & 251 & & \\
\hline Male & 82 & 19.43 & 89 & 21.09 & 171 & & \\
\hline Age & & & & & & & 0.64 \\
\hline$<60$ years & 67 & 15.99 & 87 & 20.76 & 154 & & \\
\hline$\geq 60$ years & 111 & 26.49 & 154 & 36.75 & 265 & & \\
\hline Race & & & & & & & 0.33 \\
\hline Caucasian & 115 & 27.25 & 181 & 42.89 & 296 & & \\
\hline Non Caucasian & 65 & 15.41 & 61 & 14.45 & 126 & & \\
\hline Marital status & & & & & & & 0.64 \\
\hline Married & 117 & 27.73 & 174 & 41.23 & 291 & & \\
\hline Single & 63 & 14.93 & 68 & 16.12 & 131 & & \\
\hline Level of education & & & & & & & 0.52 \\
\hline$\leq 08$ years & 126 & 29.86 & 142 & 33.65 & 268 & & \\
\hline$>08$ years & 54 & 12.79 & 100 & 23.70 & 154 & & \\
\hline Economic level $^{*}$ & & & & & & & 0.91 \\
\hline$A / B$ & 47 & 11.13 & 72 & 17.06 & 119 & & \\
\hline C/D/E & 133 & 31.52 & 170 & 40.29 & 303 & & \\
\hline Time since diagnosis & & & & & & & 0.64 \\
\hline$\leq 10$ years & 102 & 24.17 & 135 & 31.99 & 237 & & \\
\hline$>10$ years & 78 & 18.49 & 107 & 25.35 & 185 & & \\
\hline Comorbidities & & & & & & & 0.40 \\
\hline Yes & 108 & 25.60 & 150 & 35.54 & 258 & & \\
\hline No & 72 & 17.06 & 92 & 21.80 & 164 & & \\
\hline Medication Regimen Complexity Index & & & & & & & $0.02^{\dagger}$ \\
\hline Low & 91 & 21.56 & 155 & 36.73 & 246 & & \\
\hline High & 89 & 21.09 & 87 & 20.62 & 176 & & \\
\hline Satisfaction with healthcare service & & & & & & & $0.00^{+}$ \\
\hline Satisfied & 70 & 17.81 & 156 & 39.70 & 226 & & \\
\hline Dissatisfied & 98 & 24.94 & 69 & 17.55 & 167 & & \\
\hline Satisfactory knowledge & & & & & & & $0.00^{+}$ \\
\hline Yes & 123 & 29.14 & 224 & 53.09 & 347 & 82.23 & \\
\hline No & 57 & 13.51 & 18 & 4.26 & 75 & 17.77 & \\
\hline
\end{tabular}

*Based on the Economic Classification Criteria of Brazil (Brazilian Association of Research Companies - ABEP) $+\mathrm{p}$-significant value in the logistic regression model Stepwise Backward Elimination

Regarding the characteristics, the majority of the studied people were female $(59.48 \%)$, elderly $(63.25 \%)$, Caucasian (70.14), married (68.96\%), with low level of education $(63.51 \%)$, low family income $(71.81 \%)$, less than 10 years from the SAH diagnosis $(56.16 \%)$, but who already presented comorbidities (61.14\%). However, none of these characteristics had significant association with the outcome of interest $(p<0.05)$ (Table 1$)$.

In turn, the people with $\mathrm{SAH}$ who had little knowledge about their disease $(p=0.00)$, complex drug 
therapy $(p=0.02)$ and dissatisfaction with the healthcare service $(p=0.00)$ were respectively 2.1 (IC: $1.7-2.7)$, 1.4 (IC: $1.1-1.7$ ) e 1.9 (IC: $1.51-2.39$ ) times more likely not to adhere to the drug therapy.

The data in Table 2 show that most people with SAH had satisfactory knowledge about the disease, since eight questions had accuracy percentage over $70.0 \%$.
However, the low rate of accuracy in relation to two questions can be noted: only $59.50 \%$ of the adherent participants and $49.44 \%$ of the non-adherent ones were aware that, in most cases, the SAH is a silent disease, and $39.66 \%$ of the adherent participants and $28.33 \%$ of the non-adherent ones were aware that the disease can also be treated without the use of medications.

Table 2 - Distribution of people with arterial hypertension who adhered or not to the hypertensive drug therapy according to the positive attitudes in relation to the knowledge about the disease, Maringa, PR, Brazil, 2012

\begin{tabular}{|c|c|c|c|c|c|c|c|}
\hline \multirow{2}{*}{$\begin{array}{l}\text { Question in relation to the } \\
\text { knowledge about the disease }\end{array}$} & \multicolumn{2}{|c|}{$\begin{array}{l}\text { Adherent } \\
(242)\end{array}$} & \multicolumn{2}{|c|}{$\begin{array}{c}\text { Non-adherent } \\
(180)\end{array}$} & \multirow{2}{*}{$\mathbf{p}$} & \multirow{2}{*}{$\begin{array}{l}\text { Relative } \\
\text { risk }\end{array}$} & \multirow{2}{*}{$\begin{array}{l}\text { Confidence } \\
\text { Interval }\end{array}$} \\
\hline & $\mathbf{n}$ & $\%$ & $\mathbf{n}$ & $\%$ & & & \\
\hline Is high blood pressure a lifelong disease? & 192 & 79.33 & 141 & 78.33 & 0.80 & - & - \\
\hline Most times, do people with high blood pressure feel anything different? & 144 & 59.50 & 89 & 49.44 & $0.03^{*}$ & 1.3 & $1.01-1.57$ \\
\hline Is the pressure high when it is $\geq 14 / 9$ ? & 197 & 81.40 & 137 & 76.11 & 0.18 & - & - \\
\hline Can high blood pressure cause heart, brain and kidney problems? & 212 & 87.60 & 157 & 87.22 & 0.90 & - & - \\
\hline Is the treatment for high blood pressure a lifelong one? & 219 & 90.49 & 137 & 76.11 & $0.00^{*}$ & 1.7 & $1.31-2.19$ \\
\hline Can high blood pressure be treated without the use of medication? & 96 & 39.66 & 51 & 28.33 & $0.01^{*}$ & 1.4 & $1.06-1.73$ \\
\hline Do regular physical exercises help control high blood pressure? & 219 & 90.49 & 143 & 79.44 & $0.00^{*}$ & 1.6 & $1.19-2.05$ \\
\hline Does losing weight help control high blood pressure in obese people? & 230 & 95.04 & 159 & 88.33 & $0.01^{*}$ & 1.6 & $1.11-2.19$ \\
\hline Does reducing salt intake help control high blood pressure? & 241 & 99.58 & 173 & 96.11 & $0.00^{*}$ & 2.1 & $1.20-3.66$ \\
\hline Does reducing stress help control high blood pressure? & 237 & 97.93 & 166 & 92.22 & $0.00^{*}$ & 1.8 & $1.19-2.69$ \\
\hline
\end{tabular}

*p-significant value in the Pearson's Chi square test

Of the 10 questions applied to assess the knowledge of the participants, seven had statistically significant association with the non-adherence to drug therapy. The calculation of the RR showed that, in general, the little knowledge about the SAH and its treatment increases 1.3 to 2.1 times the chance that a person with $\mathrm{SAH}$ does not properly adhere to the proposed drug therapy.

\section{Discussion}

The predominance of people who did not adhere to the drug therapy identified in this study (42.65\%) is lower than that found in a research conducted in another Brazilian city, also located in the South region, which showed the predominance of $53.1 \%$ of people who did not adhere to it, using the same instrument $(\mathrm{MRCI})^{(4)}$. This difference of more than $10 \%$ could be a consequence of the distinct characteristics of the samples. In the present study, for example, there was a higher number of married people, with more than eight years of education and who belonged to the $A$ and $B$ economic levels, which positively affects the adherence process $^{(2,9)}$. However, the predominance of people who did not adhere to the drug therapy in others studies that used the Morisky-Green-Levine and Batalla tests ${ }^{(7,15)}$ and manual count of pills ${ }^{(16)}$ is lower than that found in this study, approximately $30 \%(7,15-16)$.

Biological and socioeconomic characteristics such as gender, age, marital status, level of education, economic level and race, were described in other studies as predictors of adherence/non-adherence to the SAH treatment ${ }^{(17-18)}$. However, in the present investigation, none of these variables were statistically significant to the outcome of interest. This might be partially explained by the difference of methods used to measure the nonadherence to the therapy.

One factor that has been studied in conjunction to the process of adherence/non-adherence to the drug therapy is the complexity of the therapeutic regimen. In the present investigation, the high complexity of the drug therapy can be observed in $41.71 \%$ of the participants and it is more predominant and significant among those who did not adhere. However, the existence of a relationship between the complexity of the therapeutic regimen and the adherence to the drug therapy is not always so direct or easily noted.

In any event, similarly to the results of this study, a research carried out in a city located in the Southeast region of Brazil, for example, involving 120 elderly people with $\mathrm{SAH}$, found a strong correlation between a higher complexity of the drug therapy and a low adherence to 
the treatment ${ }^{(11)}$, while a randomized study conducted in Japan, which involved 207 people with SAH, showed that there was no significant difference in the adherence to the antihypertensive drug therapy between the group that took only one pill and the control group, which took two of them ${ }^{(19)}$.

However, even without a consensus in the literature, the simplification of the therapeutic regimen has been shown to have an impact on the adherence to drug therapy. A literature review study showed that the use of medications combined in a single daily dose, rather than the free combination of the medication taken in different times, was shown to be associated with a significant increase in the treatment adherence ${ }^{(17)}$.

However, in relation to people's knowledge about the disease, the data available seem more consolidated, showing that the lack of knowledge, the beliefs and myths that patients have about their disease, the demotivation to control it, the inability to associate their behavior with the management of adverse situations and the low expectations of the result of the treatment negatively affect the adherence(3).

In the present investigation, it was observed that most people with SAH had satisfactory knowledge about the disease, and only two questions had an accuracy percentage below $70.0 \%$, which is consistent to other Brazilian studies ${ }^{(8,10)}$. The low accuracy rate, when it occurs, may be associated with the degree of knowledge of the patients about the disease or with other factors, such as the acceptance of the $C D$, the motivation to apprehend the information and even the level of education ${ }^{(10)}$.

A research conducted in Sao Paulo (SP) with 511 patients monitored by a Hypertension League showed a high degree of knowledge about the alternative ways to treat the disease, considering that more than $80 \%$ of them recognized the benefits of quitting smoking, reducing weight, practicing physical exercise and reducing alcohol intake, which positively affected adherence to treatment ${ }^{(20)}$. Similarly, a study undertaken in Pakistan with 477 people with SAH showed that those with adequate control of blood pressure levels were exactly those who had more knowledge about the disease ${ }^{(21)}$.

The fact that people with SAH had a satisfactory knowledge about the disease is very positive and at least an indication that these people are having more access to information, either by their own initiative, or due to a greater dissemination in the vehicles of mass communication, or even due to a better performance of healthcare professionals, in particular the ESF teams. Thus, it is possible to conclude that this level of assistance has been reaching its purposes, given that one of the foundations of the SAH treatment in the primary healthcare is health education, focused on lifestyle change, adherence to drug therapy when prescribed and prevention of illnesses resulting from lack of control of the disease.

Based on the facts above exposed, it can be noted that the higher the degree of patients' knowledge about the disease, the greater the self-care and the adherence to treatment. However, the problem of adherence is more complex, because the access to information about the SAH does not necessarily imply greater adherence to the control measures ${ }^{(1)}$. From this perspective, a randomized study developed in Spain with 996 people with $\mathrm{SAH}$, showed that educational interventions did not have a significant impact on the patients' adherence to the medication ${ }^{(5)}$.

This is because there is inconsistency between having information about the disease and adhering to drug therapy and controlling the BP. Thus, there is an essential difference between knowledge and practice, which means that although knowing what needs to be done, patients do not act according to such knowledge, because while the knowledge is rational, the adherence involves a multifactorial process affected by emotional, social, biological and cultural factors ${ }^{(1)}$.

In this sense, it cannot be denied that, by increasing the coverage of the primary healthcare services, provided through the implementation of the ESF, the access of the population to primary healthcare improved, allowing, among other advancements, the creation of bonds between the users and the ESF teams, which tends to support the systematic monitoring and the development of health promotion and disease prevention activities ${ }^{(22)}$. However, it can be noted that there should not be only the simple transmission of information on the part of the healthcare teams, especially the nurses, to avoid the opening of a gap between the guidance provided by the professional and its effective applicability.

Therefore, one of the main duties of nurses when providing care to patients with $\mathrm{SAH}$ and their families in the primary healthcare is to seek prevention of illnesses and promoting health. Thus, during the nursing appointments and the Hiperdia groups, professionals should perform health education actions, encouraging the supported self-care, so that people, families and groups can develop skills that enable them to act consciously in relation to changeable risk factors, among them the adherence to drug therapy ${ }^{(2)}$. 
Taking this into account, the quality of the work performed by nurses in the healthcare services is critical because providing innovative care to groups with $C D$ and their families at a UBS is essential to raise awareness among them, so that together - patient, family and professionals - they develop treatment guidelines ${ }^{(23)}$.

For the joint planning of the care, aimed at the adherence to drug therapy and control of blood pressure, it is essential the presence of the patient in the UBS. The dialogue with the professionals brings individual motivation and this, in turn, guides certain attitudes that contribute for the reduction of the BP. Regular meetings/appointments provide better monitoring of the blood pressure levels, as well as the opportunity to have more access to information, and can serve as a basis for compliance with the guidelines related to the drug and alternative therapies ${ }^{(7)}$.

From this perspective, the access to health care has been pointed out as relevant to the adherence to hypertensive treatment. Therefore, the current health policies, the easy access of patients to healthcare services and the quality of the work developed by professionals and managers directly affect the adherence process ${ }^{(17)}$. Thus, current researches confirm the strong correlation between the satisfaction with the healthcare services and the adherence/non-adherence issue ${ }^{(4,11)}$.

Despite some methodological limitations, such as the fact that the study participants were selected from those registered in the Hiperdia Program and who performed drug therapy for at least one year, which resulted in a sample mainly composed of women and elderly people, and also the different possible methods to identify the non-adherence to drug therapy, which makes it hard to compare the results found, it can be stated that the predominance of people who do not adhere to the SAH treatment in primary healthcare in the locus of the study is high and does not differ much from what has been found in other Brazilian cities. These issues, therefore, are a challenge for the healthcare sector in cities with different population sizes and located in the various regions of the country.

\section{Conclusion}

The results showed that $42.6 \%$ of the people with SAH studied were considered to be non-adherent to the drug therapy and that, although only $17.7 \%$ had little knowledge about the disease, this is a factor associated to the non-adherence to the drug therapy. Other factors associated with the non-adherence to the treatment were: complex drug therapy and dissatisfaction with the healthcare service.

These findings reinforce the need for the healthcare professionals working in the primary healthcare, particularly nurses - professionals who regularly deal with people with $\mathrm{SAH}$, the reason why the nonadherence issue should be continuously studied by nursing professionals - to work towards simplifying the therapeutic regimen, to create a greater bonding with the population and, from that, develop activities to promote health and prevent illnesses, with transfer of information and awareness of the population with $\mathrm{SAH}$ under their care about the importance of properly adhere to antihypertensive treatment agreed with the healthcare provider.

\section{References}

1. Silva LOL, Soares MM, Oliveira MA, Rodrigues SM, Machado CJ, Dias CA. "Tô sentindo nada": percepções de pacientes idosos sobre o tratamento da hipertensão arterial sistêmica. Physis: Rev Saúde Coletiva. 2013;23(1):227-42.

2. Reiners AAO, Nogueira MS. Raising hypertensive patients' consciousness about treatment compliance. Rev. Latino-Am. Enfermagem. 2009;17(1):59-65.

3. Gusmão JL, Ginani GF, Silva GV, Ortega KC, MionJunior D. Adesão ao tratamento em hipertensão arterial sistólica isolada. Rev Bras Hipertens. 2009;16(1):38-43. 4. Santa-Helena ET, Nemes MIB, Eluf-Neto J. Fatores associados à não adesão ao tratamento com antihipertensivos em pessoas atendidas em unidades de saúde da família. Cad Saude Pública. 2010; 26(12):2389-98.

5. Guirado EA, Ribera EP, Huergo VP, Borras JM. Knowledge and adherence to antihypertensive therapy in primary care: results of a randomized trial. Gac Sanit. 2011;25(1):62-7.

6. Morgado M, Rolo S, Macedo AF, Pereira L, CasteloBranco M. Predictors of uncontrolled hypertension and antihypertensive medication nonadherence. J Cardiovasc Dis Res. 2010;(4):196-202.

7. Dosse C, Cesarino, CB, Martin JFV, Castedo MCA. Factors associated to patients' non-compliance with hypertension treatment. Rev. Latino-Am. Enfermagem. 2009;17(2):201-6.

8. Strelec MAAM, Pierin AMG, Mion-Junior D. A influência do conhecimento sobre a doença e a atitude frente à tomada dos remédios no controle da hipertensão arterial. Arq Bras Cardiol. 2003;81(4):43-8. 
9. Sociedade Brasileira de Cardiologia, Sociedade Brasileira de Hipertensão, Sociedade Brasileira de Nefrologia. VI Diretrizes Brasileiras de Hipertensão. Arq Bras Cardiol. 2010;95 Supl1:1-51.

10. Pucci N, Pereira MR, Vinholes DB, Pucci P, Campos ND. Conhecimento sobre Hipertensão Arterial Sistêmica e Adesão ao Tratamento Anti-Hipertensivo em Idosos. Rev Bras Cardiol. 2012;25(4):322-9.

11. Obreli-Neto PR, Prado MF, Vieira JC, Fachini FC, Pelloso SM, Marcon SS, Cuman RKN. Fatores interferentes na taxa de adesão à farmacoterapia em idosos atendidos na rede pública de saúde do Município de Salto Grande. Rev Cienc Farm Basica Apl. 2010;31(3):229-33.

12. Osamor PE, Owumi BE. Factors Associated with tratament compliance in hypertension in Southwest Nigeria. J Health Popul Nutr. 2011; 29(6):619-28.

13. Santa-Helena ET, Nemes MIB, Eluf-Neto J. Desenvolvimento e validação de questionário multidimensional para medir não adesão ao tratamento com medicamentos. Rev Saude Pública. 2008; 42(4):764-7.

14. Melchiors AC, Correr CJ, Llimos FF. Tradução e Validação para o Português do Medication Regimen Complexity Index. Arq Bras Cardiol. 2007; 89(4):210-8.

15. Carvalho ALM, Leopoldino RWD, Silva JEG, Cunha CP. Adesão ao tratamento medicamentoso em usuários cadastrados no Programa Hiperdia no município de Teresina (PI). Ciênc Saúde Coletiva. 2012; 17(7): 1885-92.

16. Garcia JE, Claros NM, Ruiz AL, Gurrea DFB. Cumplimiento farmacológico en el tratamiento de la hipertensión arterial: Revisión de los estudios publicados entre los años 1975 y 2011. Semergen: Medic Famil. 2012;38(5):292-300.

17. Gupta AK, Arshad S, Poulter NR. Compliance, Safety, and Effectiveness of Fixed-Dose Combinations of Antihypertensive Agents: A Meta-Analysis. Hypertension. 2010;55(2):399-407.

18. Veras RFS, Oliveira JS. Aspectos sócio-demográficos que influenciam na adesão ao tratamento antihipertensivo. Rev RENE. 2009;10(3):132-8.

19. Matsumura K, Arima H, Tominaga M, Oshtsubo T, Sasaguri T, Fujii $K$, et al. Does a combination pill of antihypertensive drugs improve medication adherence in Japanese? A randomized controlled trial. Circ J. 2012;76(6):1415-22.

20. Serafim TS, Jesus ES, Pierin AMG. Influence of knowledge on healthy lifestyle in the control of hypertensive. Acta Paul Enferm. 2010;23(5):658-64.
21. Almas A, Godil SS, Lalani S, Samani ZA, Khan $\mathrm{AH}$. Good Knowledge about hypertension is linked to better control of hypertension a multicenter cross sectional study in Karachi, Pakistan. BMC Res Notes. 2012;5:579.

22. Costa JMBS, Silva MRF, Carvalho EF. Avaliação da implantação da atenção à hipertensão arterial pelas equipes de Saúde da Família do município do Recife (PE, Brasil). Cienc Saúde Coletiva. 2011;16(2):623-33.

23. Elsen I, Souza AIJ, Prospero ENS, Barcellos WBE. O cuidado profissional às famílias que vivenciam a doença crônica em seu cotidiano. Cienc Cuid Saúde. 2009;8 Supl:11-22.

Received: Aug 22 2013 Accepted: Mar. $13^{\text {th }} 2014$ 